\title{
Gastric and pancreatic metastases from pleomorphic lung carcinoma
}

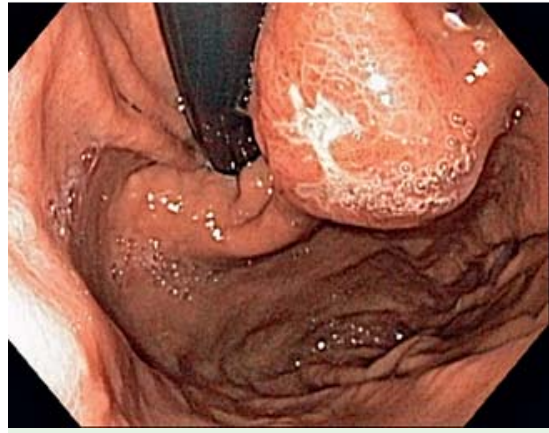

Fig. 1 Esophagogastroduodenoscopic (EGD) image of a 1.5-2-cm submucosal erythematous lesion at the cardia with overlying erosions in an elderly patient with non-small-cell carcinoma of the lung.

A 76-year-old man with a newly diagnosed, biopsy proven, non-small-cell, pleomorphic lung carcinoma was found to have multiple lesions in the pancreas on a staging computed tomography (CT) scan. The lesions were of uncertain significance and there was no other evidence of metastasis in the chest or abdomen. The patient underwent endoscopic ultrasound fine needle aspiration (EUS-FNA) for further evaluation of the lesions in the pancreas. On pre-EUS upper endoscopy, a $1.5-2-\mathrm{cm}$ subepithelial lesion with overlying erythema was visualized on retroflexion at the cardia ( $\bullet$ Fig. 1 ).

EUS examination using a linear echo-endoscope revealed three hypoechoic, welldefined lesions measuring $1.5 \mathrm{~cm}, 2.5 \mathrm{~cm}$, and $1.5 \mathrm{~cm}$ in the head, body, and tail of pancreas, respectively ( $\bullet$ Fig. 2 ).

EUS imaging of the subepithelial lesion in cardia revealed a hypoechoic lesion in the gastric wall arising in the submucosa, with an intact muscularis propria (๑ Fig. 3).

EUS-FNA of the subepithelial lesion in the gastric cardia and of the pancreatic body mass was carried out using different EUSFNA needles ( $\bullet$ Fig. 4).

Cytopathology of both lesions was consistent with pleomorphic carcinoma, compatible with metastasis from lung cancer. The patient was referred to medical oncology for further management and started on chemotherapy.

Metastasis to the pancreas is extremely uncommon [1]. Lung cancer metastasis to

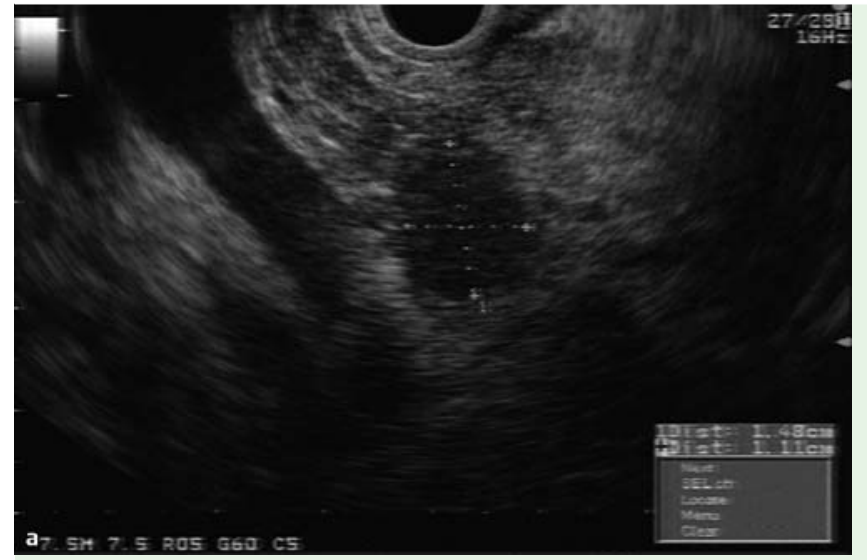

Fig. 2 Endoscopic ultrasound (EUS) images of the three round, hypoechoic pancreatic masses: a a $1.5-\mathrm{cm}$ mass in the head of the pancreas; $\mathbf{b}$ a $2.5-\mathrm{cm}$ mass in the body of the pancreas; and c a $1.5-\mathrm{cm}$ mass in the tail of the pancreas.
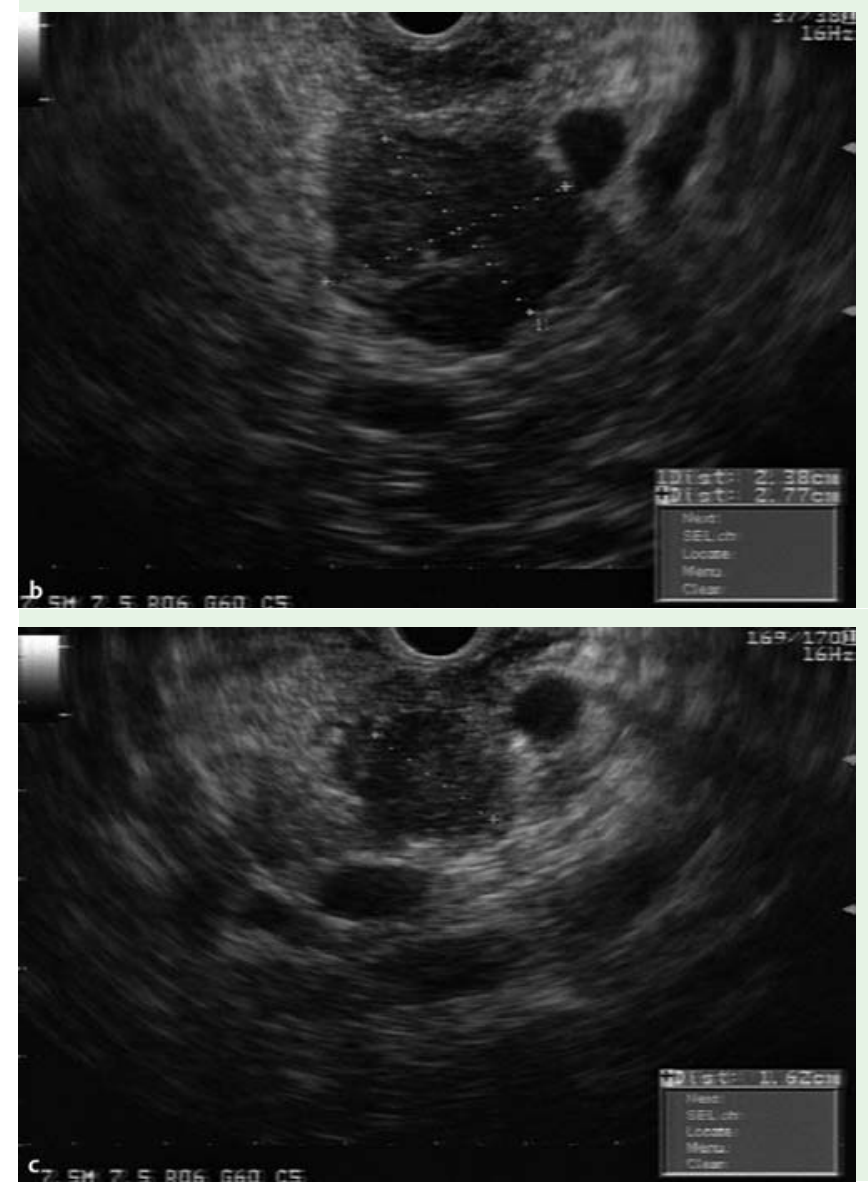

pancreas or stomach is also rare [2,3], and these patients may present with pancreatitis, obstructive jaundice, or acute cholangitis [3-6]. Our case is unique since the multiple metastatic lesions in the head, body, and tail of pancreas, as well as one lesion in the gastric cardia, were discovered as incidental findings during a staging scan. To our knowledge, con- current lung cancer metastasis to the stomach and pancreas has never been reported before. Esophagogastroduodenoscopy/EUS-FNA provided definitive diagnosis and directly impacted further management. Furthermore, the gastric lesion was masquerading as a subepithelial mass and was not seen or suspected on CT scan. 


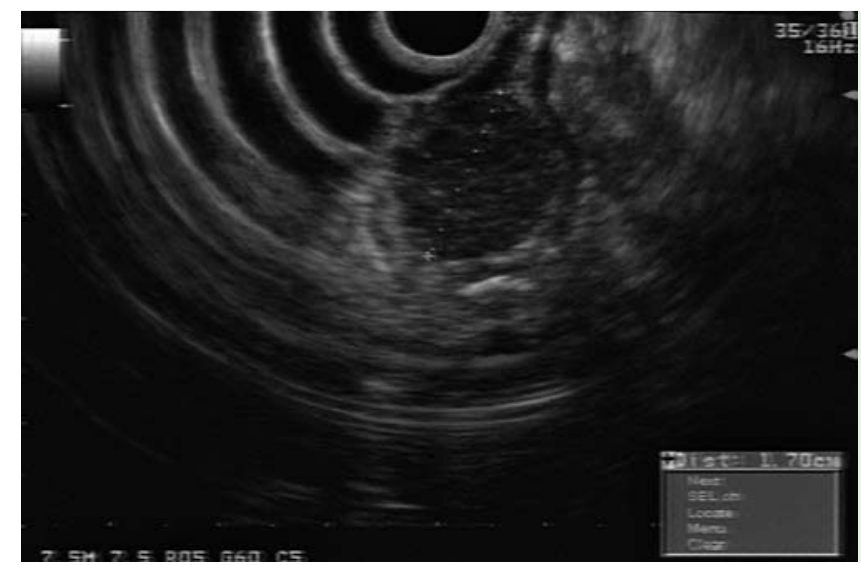

Fig. 3 Endoscopic ultrasound (EUS) image of the submucosal lesion with intact muscularis propria underneath.

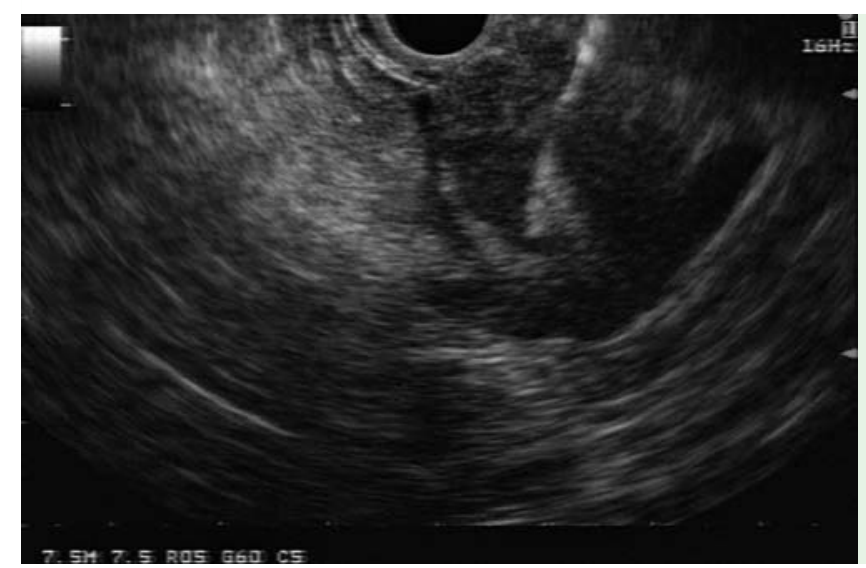

Fig. 4 Endoscopic ultrasound fine needle aspiration (EUS-FNA) of the $2.5-\mathrm{cm}$, round, hypoechoic mass in the body of the pancreas.

Endoscopy_UCTN_Code_CCL_1AZ_2AB

\section{Competing interests: None}

A. M. Ioncica ${ }^{1}$, M. Atiq ${ }^{2}$, J. H. Lee $^{2}$, A. Saftoiu' ${ }^{2}$, M. S. Bhutani ${ }^{2}$

1 Department of Gastroenterology and Hepatology, University of Medicine and Pharmacy of Craiova, Craiova, Romania

2 Department of Gastroenterology, Hepatology, and Nutrition, University of Texas - MD Anderson Cancer Center, Houston, Texas, USA

\section{References}

1 Crippa S, Angelini C, Mussi C et al. Surgical treatment of metastatic tumors to the pancreas: a single center experience and review of the literature. World J Surg 2006; 30: $1536-1542$

2 Casella G, Di Bella C, Cambareri AR et al. Gastric metastasis by lung small cell carcinoma. World J Gastroenterol 2006; 12: 4096-4097

$3 \mathrm{Kim}$ KH, Kim CD, Lee SJ et al. Metastasis-induced acute pancreatitis in a patient with small cell carcinoma of the lung. J Korean Med Sci 1999; 14: 107-109

4 Liratzopoulos N, Efremidou EI, Papageorgiou MS et al. Extrahepatic biliary obstruction due to a solitary pancreatic metastasis of squamous cell lung carcinoma. Case report. J Gastrointestin Liver Dis 2006; 15: 73 - 75

5 Kyriazi MA, Sofoudis C, Katsouri $M$ et al. Acute cholangitis due to pancreatic metastasis from squamous cell lung carcinoma: a case report and review of literature. Cases J 2009; 2: 9113

6 Pericleous S, Mukherjee S, Hutchins RR. Lung adenocarcinoma presenting as obstructive jaundice: a case report and review of literature. World J Surg Oncol 2008; 6: 120

\section{Bibliography}

DOI $10.1055 / \mathrm{s}-0030-1256686$

Endoscopy 2011; 43: E317-E318

(c) Georg Thieme Verlag KG Stuttgart . New York . ISSN 0013-726X

\section{Corresponding author}

\section{S. Bhutani}

Department of Gastroenterology, Hepatology, and Nutrition

University of Texas - MD Anderson Cancer Center 1400 Pressler Street

Unit 1466

Houston, TX 77030

USA

Fax: 713-563-4408

Manoop.Bhutani@mdanderson.org 